\title{
Science \& Technology Revolution and Human Language
}

\author{
Stephen Ondago Oduor ${ }^{1}$, Jingjing Wang ${ }^{2}$ \\ ${ }^{1}$ School of Chinese Language and Literature, Wuhan University, China \\ ${ }^{2}$ School of International Chinese Education,Macao University of Science and Technology
}

Keywords: Science and Technology Revolution, Language Technology, Human Language.

Abstract: From the industrial revolution to the modern society of the $21^{\text {st }}$ century, science and technology have promoted the development of the language. With the advent of the information age, the processing of natural language has become a key task in information processing. Therefore, language science and technology are receiving more and more attention. The vocabulary and combination of science and technology have a profound impact on change, the improvement of the communication status of scientific and technical terms, and the contact and integration between languages. As the understanding of language continues to deepen, the science and technology of language also undergo extensive cross-cutting with other fields of science. At the same time, the development of language is influenced by various political, economic and cultural factors.

\section{Introduction}

Since the middle of the $18^{\text {th }}$ century, mankind has experienced three scientific and technological revolutions, greatly improving productivity and consolidating the dominance of capitalist countries. In order to adapt to the development of science and technology, capitalist countries generally strengthen their support for scientific research, and greatly increase support for science and technology and capital investment. With the continuous advancement of science and technology, major changes have taken place in all aspects of daily life, such as clothing, food, housing, transportation. At the same time, it has increased the gap between the rich and the poor worldwide and promoted changes in social production relations around the world.Language is closely related to the three technological revolutions of human history, and this relationship is becoming increasingly close with the development of science and technology.

\section{The Impact of the Scientific Revolution on Language}

When referring to the relationship between language and society, the Social linguist Chen Yuan notes that, "When social life changes gradually and drastically, language_— as a social phenomenon, and as a tool of social communication - changes in no uncertain terms with the pace of social life." With the emergence of symbols, language has been given a new meaning, and science and technology are linked, human through the social experience described by language, the 
symbol recorded, become a scientific and technological symbol.With the richness of language and the perfection of words, the advantages of language to promote human development, especially scientific development, are reflected. ${ }^{2}$ Many new scientific and technological terms and vocabulary have entered human language, and the influence of the scientific and technological revolution on language is becoming more and more profound.

The impact of the scientific and technological revolution on language is mainly reflected in vocabulary. From the results of lexical evolution, there are three common phenomena: new word generation, old word demise and word replacement.The emergence of new words is related to the emergence of new things in reality.With the development of industrial and agricultural production and science and technology, new things emerge in an endless stream, and language produces new words for the need to express these new occurrences. ${ }^{3}$ For example, “登月 "moon landing, missile“导弹”, courseware“课件”, nuclear bomb“核弹”, nano“纳米”, pollution“污染”, container“集装箱”, hovercraft“气垫船”, cloning“克隆”,blog“博客” and so on are all words that appear in the language.Completely new words such as wăsī“瓦斯” (gas) in English,Kēdá “柯 达”(Kodak), bleep (referring to the sound of electronic instruments), zap (the flying sound of shells), and suchlike are rare. It is guaranteed that new words are used as tools to express new meanings and are easily accepted by society. The word substitution is characterized by changing the name of a certain kind of realistic phenomenon, which itself has not changed or not changed significantly.Word substitution is also related to changes in people's understanding. For example, after the founding of New China, many words in Chinese were considered to reflect the hierarchical concept of the old society and changed the original statement, such as: sīlìnguān“司令官”sīlìngyuán “司令员 ”(commander-in-chief),chúzi “嘚子”—chuīshìyuán“炊事员” (The cook/kitchen staff ), băixìng “百姓”——rénmín“人民” (the people).In addition, the words in the basic vocabulary are stable and not changeable, but some words are gradually being updated. Such as: jiăo “ 脚”——足 ”zú( foot),liăn“ 脸” ” miàn“面”(face),yăn“眼”___ “目”mù(eyes ).The core vocabulary is relatively stable, and the general vocabulary word replacement is more frequent, which is related to social changes. For example, in ancient China, it was said that it was a world for thirty years. In the early Tang Dynasty, it replaced the "world" with "generation" by avoiding the embarrassment of Emperor Taizong Li Shimin.

The development of vocabulary after the reform and opening up has the characteristics of trend rapidity and convergence. According to Hu Zhiling (2007:69),"Science,technology and economic activities are the most important and dynamic activities in today's human life, and many new words come directly from them to meet the needs of the emerging new situation." 4 The reason for the new words is the continuous development of society, the emergence of new occurrences, people need to understand and refer to these happenings, we must name it to meet the needs of communication.At the same time, the development and change of society has improved people's cognitive ability. People have deepened their understanding of what is known, discovered new features that were unknown to the previous generation, and created new words in order to record and refer to these new understandings. For example, “computers(计算机), software(软件), remote sensing(遥感), protons(质子), neutrons(中子), electronics(电子)" and so on and due to the development trend of the disyllabic word, some monosyllabic words or polysyllabic phrases have obtained a new 
two-syllable form in communication, and new words have been added to the language. The main word formation methods of new words are compound, additional and abbreviated.

With the development of computer networks, the commercial Internet was formed in the 1990s. Since the end of the 20th century, a large number of new communication media have been developed.Network media can be divided into two main categories: new media that comes with the network and traditional media that migrate to the network. The network media presents the characteristics of "all- media". For example, television has integrated visual and audio functions into one media. Therefore, online media is more comprehensive. All the information load methods created by humans in the past can basically be networked on the internet.This comprehensive feature has turned the Internet into"hypermedia" and "all-media", and has become a database and functional platform for all media in the language; at the same time, it has a tendency of "fragmentation."Many of the new media generated by the Internet are mostly limited to "micro-media", such as Weibo, SMS, WeChat, micro video and so on.In the Internet era, especially the popularity of text messages and WeChat, people are gradually forming the habit of using fragmenting time to disseminate information, receive information and process information.The benefits of fragmentation is that there is a wide range of sources of information, the ability to communicate in a timely and fast manner, and the "self-media" nature. Publishing houses, magazines, newspapers, radio stations, television stations, etc., generally have full-time teams of varying sizes, all have a review system for publishing and broadcasting content, and even have a strict set of "gatekeeping" procedures. With the advent of modern high-tech things like the Internet and wireless communications, there are countless new words that have emerged in the language.In 2011,Professor David Cristal ,a British linguist published the world's first textbook, "Network Linguistics: Student Guide", which provided a comprehensively summarized and systematically expounded the existing knowledge and achievements of network linguistics. At present, the research field of network linguistics has expanded from linguistics to pedagogy, communication, sociology, psychology, law and other disciplines. However, the theoretical systems and research methods of network linguistics have yet to be further improved. ${ }^{5}$ For example, new words in the Internet have appeared in Chinese. With the rapid development of the network, the network vocabulary has been rapidly developed.And it is characterized by simplicity, personalization, visualization, intuitiveness and non-standardity.

\section{The Influence of Scientific and Technological Revolution on the Form of Language Combination}

According to Huang(2006:202),"Words are the smallest units of language that can be used independently,and "Independent use" means that words can be spoken or used alone; "minimum" means that words cannot be expanded, that is, no other components can be inserted in the words, even the words composed of two morphemes cannot be separated." 6 The scientific and technological revolution not only has an impact on the vocabulary of language, but also has a profound impact on the combination of language. The advancement of science and technology and the competition of society make the pace of human life faster, and the speed and efficiency of work are expressed in language, that is, language change becomes more and more economical and concise.

In the 20 years since the beginning of the new era, another striking change in the Chinese vocabulary system has been the surge in transliteration of foreign words and the emergence of a 
large number of alphabetic words. The "New Words and New Language Dictionary"edited by Li Xingjian and the "Chinese New Word Dictionary" edited by Li Daren are the objects of investigation and comparison. The statistical result are: there are 1.5 foreign words in the new Chinese words for every 100 new words in Chinese.Foreign words absorbed between 1979 and 1989 accounted for about 3\% of the total number of new words. The main reason for this phenomenon is related to social factors, namely culture, economy, politics and so on.

Foreign words, also known as loan words, refer to the sounds and meanings of words borrowed from foreign languages. For example, Fălánxī(法兰西 )France, Bāěrgàn 巴尔干 (Balkan), bàng( 镑)Pound,jiālǔn(加仑) Gallon, mótèr(模特儿) Model,mótuō(摩托) Motorcycle, mădá(马达) Motor, yōumò(幽默) Humor, làngmàn(浪漫) Romance, qǔdì(取缔 )Banning, jǐngqì(景气)Boom, hădá(哈达) Hada,lăma (喇嘛) Lama, etc. According to the absorption methods and structures of foreign words, they are roughly divided into four categories.

The first category is transliteration, such as àlínpǐkè( 奥林匹克 ) is transliteration of Olympics; xiūkè(休克)shock; pūkè(扑克)poker;sūdá(苏打) soda;bāshì(巴士) bus; pútao(葡萄) grape; kāfêi(咖 啡) Coffee; shāfā(沙发)is transliteration of Sofa ,as dísikē(迪斯科 ) is transliteration of disco in English. Some choose to translate Chinese characters with the same syllables or similar meaning or similarity as foreign langauges such as, kǔli(苦力)coolie, luóji(逻辑 )logic, yōumò(幽默 )humor, mótèr (模特儿) models, and wéitāmìng (维他命) vitamins.

The second type is partial transliteration or transliteration of phonetic meaning,translating the first half of foreign language. For example, the first semitone of the foreign language "romanticism" is translated into "romance", the second half is translated into "ism", and the "romanticism" is synthesized. There are also converse transliterations such as "Ice-cream".

The third category is the transliteration followed by the annotation of Chinese morphemes representing the meaning class, and the transliteraion of the whole word followed by a thesaurus.For example, the "kăchē" of truck is the transliteration of kă(truck), and the"chē"(car) ."Bālěi" is a transliteration of the ballet.The "Shādingyú"is a transliteration of sardine and so on.

The fourth category is the borrowing form, and the other is the letter-based borrowing word, also known as the letter word.A word that is directly combined with foreign abbreviations or Chinese characters. It is not a transliteration but original borrowing, which is a new form of loanwords in Chinese. For example, "VS", a shortened variant of English Versus.Others indicates the comparison of the two sides such as, MTV an abbreviated variant of Music TV, and CT an abbreviated variant of English CT scan or Computerized tomography.Some have Chinese related morphemes after the letters. For example, B Ultrasound, BP machine. One is to borrow Chinese characters in Japanese, which is a word that Japanese people directly borrowed from Chinese characters. Chinese borrowed back but maintained reading the sounds of Chinese characters without reading Japanese pronunciation, which is known as Chinese character borrowing form.For example, gymnastics(tǐcāo, 体 操 ), prosperity/boom(jǐngqì, 景 气 ),subjectivity (zhǔguān, 主 观 ), extradition(yǐndù, 引渡), ban(qǔdì, 取缔), gas(wăsī, 瓦斯), tea ceremony(chádào 茶道), haiku(páijù, 俳句), communism(gòngchăn, 共产), elements(yuánsù ,元素), capital(zīběn, 资本), direct(zhíjiē, 直接), justice party (Zhèngyìdăng, 正义党), etc.

In addition to the regular way in which loanwords are integrated into Chinese, the sinicization (localization) of loanwords makes the foreign colors of loanwords gradually change with the passage of time and other degrees of integration into Chinese. This process of sinicization is mainly includes the following aspects:

(1) Some loanwords have a long history of input,so it is almost difficult to recognize their alien identity without tracing their origin,especially those transliterated from foreign words.For 
example,in the Han Dynasty, with the introduction of Buddhisms'results“结果”and strict“严格” and other words.

(2) Loanwords explain the dual- tone.The double syllable is a major law in the development of Chinese vocabulary. The double syllable Chinese vocabulary is mainly determined by the social communicative function of the language. The main principle of Chinese dual-tone is to retain the original information, and the loanwords are mostly syllables. While Chinese is centered on syllables and tends to adopt double syllable word. When many foreign words are transliterated into Chinese at first, many words have been simplified into the disyllabic words in Chinese. For example, beer“啤酒”, cigar“雪茄”, etc.

(3) The transliteration component morpheme. As component transplanted from other national languages, loanwords accept the transformation of Chinese and gradually break away from the original word-making environment. With the development of society and language, loanwords free to participate in new word-making and become more and more like the inherent morphemes of native Chinese.For example, transliteration of "xiù"(show) such as"xuănxiù "(talent show ), "shízhuāngxiù "(fashion show) and so on. The localization of loanwords refers to the process of "localization", which is an important way to maintain the characteristics of the national language and enrich the national language.

\section{The Improvement of the Communicative Status of Scientific and Technical Terminology}

While the modern scientific and technological revolution has changed the way people work and their lifestyles, it has also exerted a significant influence on the appearance of language, especially the lexical system. This is manifested in two aspects: on the one hand,the emerging scientific terms account for the majority of new words and expressions. As Zhang Zhi emphasizes that,"In the broad sense of the new word, there is an explosion in the hundreds of thousands every year all over the world ",He observed that, "There are more than 100,000 new jargon words added every year in various disciplines and industries all over the world, and more than 300 new chemical termilogy are added every month. So It can be seen that most of the new words produced each year are terms." Most of the 6000 words collected in the third edition of merriam-websters's New International Dictionary supplement are terminology. Esperanto has 6000 basic words, of which there are more than 4000 internationally used scientific and technical words. In 1973, the term published in the former Soviet Union (new words and new meaning dictionary) accounted for $80 \%$ of the total number of words. ${ }^{8}$ Although the number of newly produced scientific terms is large, it does not directly affect social life like the universal lingua franca. According to the degree of socialization of terms, it can be divided into three categories: The first kind, is a narrow-ranging specialty also known as very narrow scope of specialzed words. The second category is the socialized terminology of Mandarin, and the third category is the medium between the two words that have not yet been socialized .On the other hand, the importance of technical terms in everyday communication is increasing. The modern revolution of science and technology brings to human society a high-tech era, this revolutionary change has highlighted the importance of scientific terms in peoples' social life . Scientific terminology has become a symbol that people must use in their work, not only in high-tech enterprise staff but also in dealing with technical terms. The general staff of science and technology enterprises should deal with scientific and technical terms, that is, the staff of general public institutions, and they should always be exposed to scientific terms in office automation and 
information networks.With the wide application of high and new technology in daily life, it provides people with abundant food, clothing and comfortable living. The continuous emergence of new scientific and technological products has greatly improved the scientific and technological content and quality of life of people's lives, and changed people's life concepts and lifestyles.

In the lives of contemporary people, high-tech such as videophone “可视电话”, home nanny “家庭保姆” , nanotechnology “纳米技术” and other high technology have been widely used.In general, the universal promotion of information network technology has improved people's quality of life, and at the same time, it has enabled people to master high-tech knowledge and actively learn scientific terms to become a fashionable.

\section{The Impact of the Scientific and Technological Revolution on the Contact and Integration of Languages}

The language changes caused by the contact of different societies mainly includes unsystematic vocabulary borrowing, language alliance and systematic infection, language substitution and low-level residue, common written language or the level of national/ethnic common language, pidgin and lingual franca. The results of language contact are closely related to the geographical distance, the degree of contact, the difference in population, economic and cultural level of the society in which the contact occurs. The situation of adopting foreign languages as their common written language can be roughly divided into three categories: (1) Under a unified country, one nation borrows the language of other nationalities as her common general written language. A typical example is the adoption of Chinese as a general written language for Zhuang people and other Chinese in China; (2) Borrowing the written language from other countries as the common written language. For example, Vietnam adopted Chinese as a general written language; (3) Territoy Invasion: because a country invaded another country, and forced the occupied country to use the written language of the victorious country. This is typical of France's occupation of England by the normans, which made French once the universal written language of the United Kingdom.During this period, English borrowed a large amount of words from French.For example, (国家,guójiā)state, nation(mínzú, 民族), parliament(guóhuì, 国会), army (jūnduì, 军队), court(fãtíng, 法庭),hold court trial (shěnpàn, 审判), administration of justice(sīfă,司法), officer(jūnguān,军官), fine/happy(měihăo, 美好), people（rénmín,人民）, honor（róngyù,荣誉）, battle (zhànyì,战役), enemy (dírén,敌人), and so on were all borrowed from French.

Trade contacts, cultural exchanges, immigrants, war and conquests and all other forms of contact between the people will lead to language contact.There are different types of language contact ,among which the most common one is the borrowing of words.Ye (1997:208), argues that "As long as there is contact between the societies, there will be borrowing of words.Each language has a certain number of loan words. The borrowing of words are also known as loanwords. It refers to the sound and meaning of words that are borrowed from foreign languages." The scientific and technological revolution has accelerated the exchanges between the various ethnic groups or nationalities, and the contact of language has brought about the mixture and mix of languages. For example, a large number of English words have emerged in Chinese language articles, for example, British Broadcasting Corporation (BBC), Linguistics Committee Education(CLISE) , Deutsche Academic Exchange Center(DAAD), European Security and Cooperation Conference (CSCE) and so on. In short, the intensity of social contact determines the limits of borrowing words.For example, Japanese borrowing a large number of Chinese words is a good example.As the cultural situation changed later, Japanese used borrowed Chinese as a material 
to create many new words, and Chinese borrowed some of the words from Japanese, such as doctors (博士), politics(政治), cadres(干部), and so on.

On the one hand, the advancement of science and technology has accelerated the pace of integration of various national languages. On the other hand, the languages of many ethnic minorities has disappeared. The phenomenon of language substitution occurred, which Stalin called "language fusion."As noted by Stalin "In the process of integration, usually one of the languages becomes the victor, retains its own structure and basic vocabulary, and continues to develop according to the inherent laws of its own development,while the other language gradually loses its essence and gradually die." 10 Usually, language substitution in a social group is the result of contact with other languages, and the degree of contact is deeper than unsystematic loan words and system infections. Language substitution has occurred frequently in human history, and it is now on the trend of increasing, which has led to the phenomenon of extinction and endangerment of the language that is currently of great concern worldwide.Therefore, UNESCO adopted a resolution in 1999 to observe February $21^{\text {st }}$ as the World Mother Tongue Day, every year and promote the use of mother tongue to preserve language and cultural diversity. On the one hand, language substitution promotes social integration, and the formation and development of a country are closely related to language replacement. On the other hand, language substitution objectively reduces the diversity of language and culture, and many unique cultures have withdrawn from the historical arena as the carrier disappears.

\section{Conclusion}

Although science ahnology have potential negative effects, they will still be an important factor in determining the future of society and will actively promote the development of human society to modernization. "Science and technology is the primary productive force", which is the engine that drives the progress of human history.Science and technology has brought about the development of the world economy and promoted the evolution of languages. These changes include the emergence of new words and new language expressions, language invasion and counter-invasion, as well as the weakening and extinction of languages.

\section{References}

[1] Chen Yuan. Chen Yuan's Linguistics [M]. Shenyang: Liaoning Education Press, 1998.

[2]Guo Lei. Language Culture and Science and Technology Progress-The Contribution of Language to the Progress of Science and Technology in the World [J]. Science and Technology Association Forum, 2007 (3): 2

[3] Ye Yisheng, Xu Tongyu. Outline of Linguistics [M]. Beijing: Beijing Publishing Press, 1997: 244.

[4]Hu Zhilin. Linguistics Course [M]. Beijing: Beijing Publishing Press, 2007: 69

[5]Baidu Encyclopedia //http:baike.baidu.com/view/6639915.htm

[6]Huang Borong. Modern Chinese Volume [m]. Beijing: Peking University Press, 2006: 202.

[7]Zhang Zhiyi, Zhang Qingyun. Trends and selection of New Words in the New era [J].1999,(3).

[8]Zhang Jianmin. New vocabulary variation in mainland China since the reform and opening up to 
the outside world [J]. Linguistic Applications, 1996, (1).

[9]Ye Yisheng, Xu Tongyu. Outline of Linguistics [M]. Beijing: Beijing Publishing Press, 1997: 208.

[10]Stalin. Marxism and Linguistics [M]// Stalin's Anthology: Vol. Beijing: People's Publishing House, 1979: 520. 